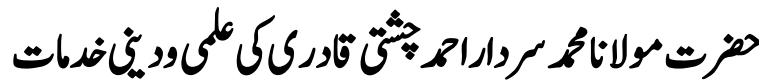

\section{The Educational and Religious Contributions of Hazrat Molana Sardar Ahmad Chishti Qadri)}

Faqir Muhammad ${ }^{*}$

Professor Dr. Matloob Ahmed ${ }^{* *}$

\begin{abstract}
Hazrat Allama Sardar Ahmad is Pakistani and belongs to Faisalabad. He born on 22 September, 1906 in Diyal Gerh, Gordaspur Hindustan. He established a great Islamic Institute with the name "Mezherul-Islam Jamia Rizvia Jhang Bazar Faisalabad. He was great Islamic learned personality, Speaker, Teacher, Sufi Saint, Writer of many books and Faqih who had excellent command on Islamic Jurisprudence and was known by his students and followers as "Mohaddis-i-Azam" Pakistan. He was the son of great personality Choudhry Miran Buksh Chishti. He was also the organizer of "All India Sunni Conference" and took active part in the movement of Pakistan. He produced many Ulamas with full knowledge of Quran, Hadith, Fiqh, Arabic Language and Literature, Islamic history, Ilm-ul-Kalam, Islamic Political, Social, Economic Thoughts. In modern Islamic World, a great number of Ulamas are delivering Islamic teachings and services which have gained their education from the Jamia Rizvia Faisalabad. He was adherent spiritually with Shah Muhammad Taj-al-Haq of Chishti Sufi Order. He died on 29 Dec, 1962 and his Shrine is located in Sunni Rizvi Jamia Masjid JhangBazar, Faisalabad.
\end{abstract}

Keywords: Diyal Gerh, Learned Personality, Saint, Jurisprudence, Mohaddis-i-Azam, Organiser, Movement, Ulamas, Delivering, Spiritually, Shrine.

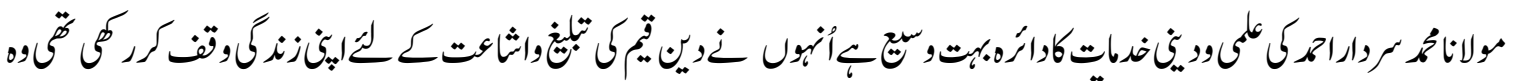

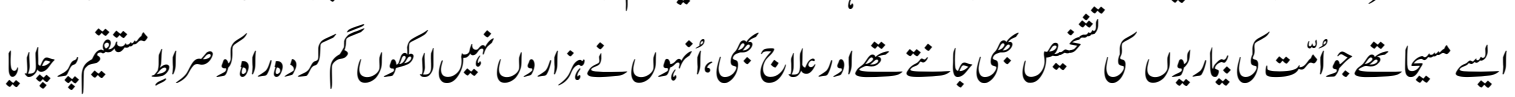

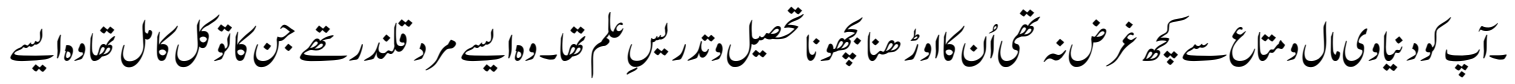

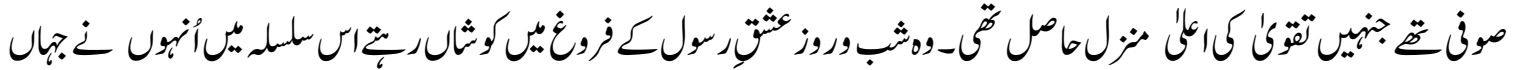

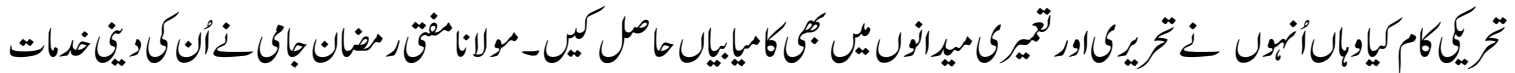

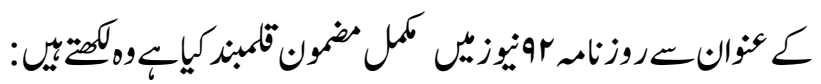

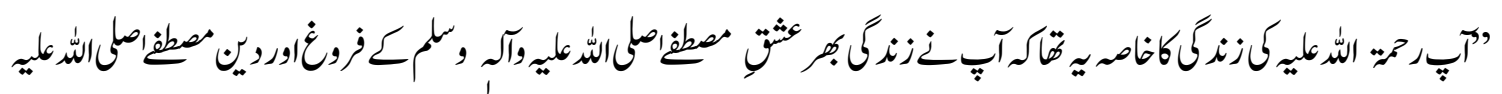

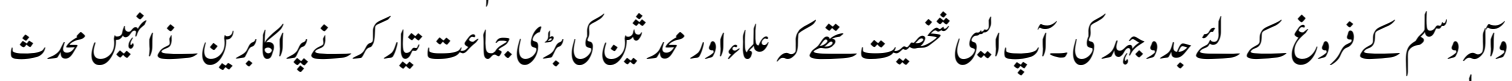

\footnotetext{
${ }^{*}$ M Phil Research Scholar, G.C University Faisalabad.

Email: faqirmfsd@gmail.com

${ }^{* *}$ Chairman, Department of Arabic and Islamic Studies University of Faisalabad.

Email: dr.matloobahmed786@yahoo.com
} 


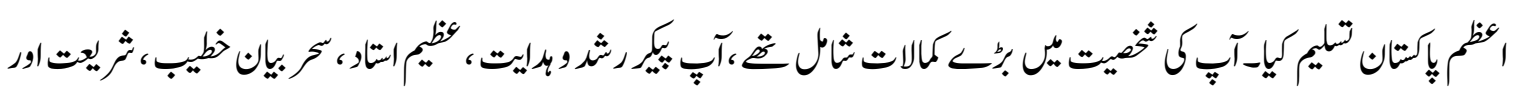

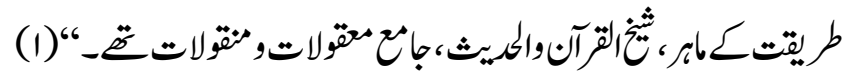
ولاوت إسعاوت

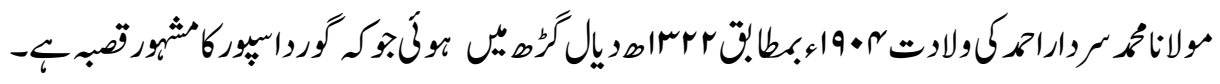

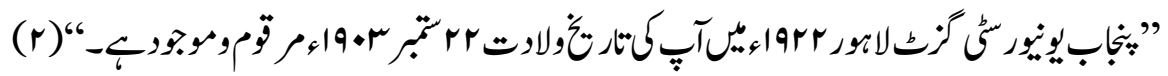

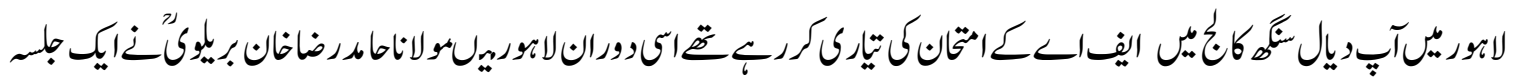

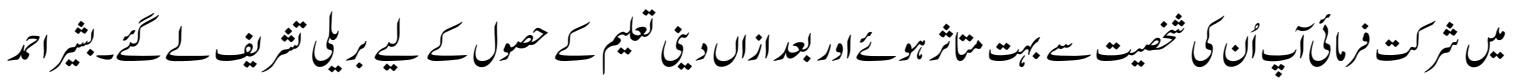

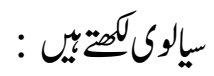

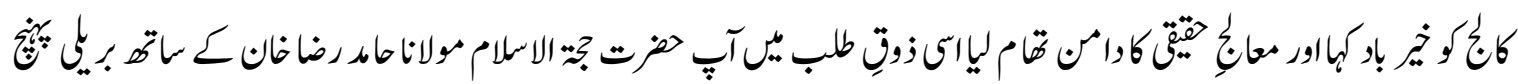

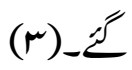

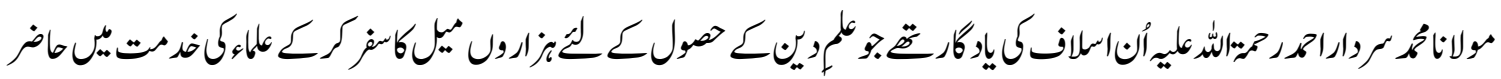

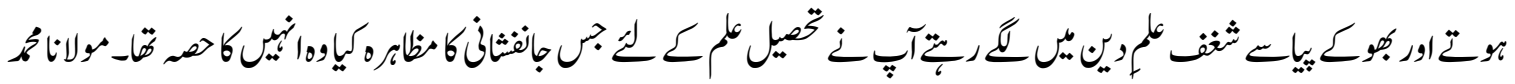
صاوت كمب: بي:

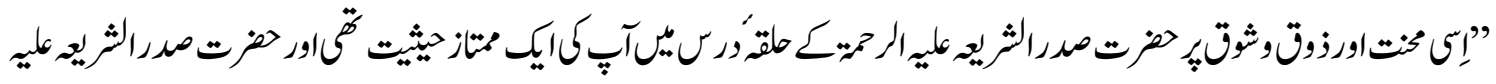

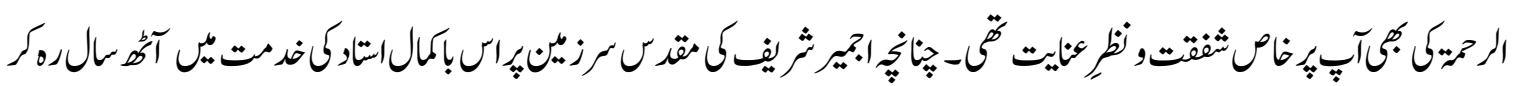

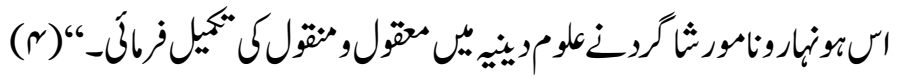

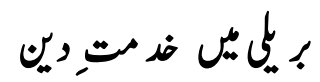

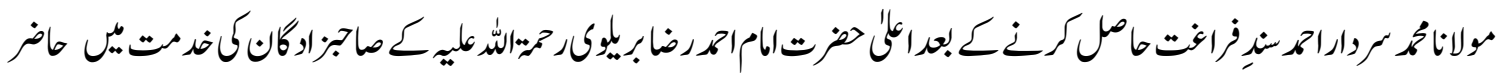

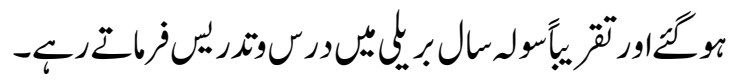

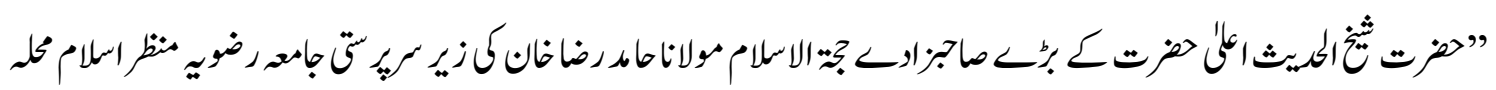

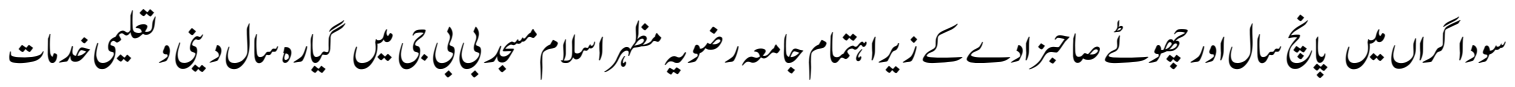

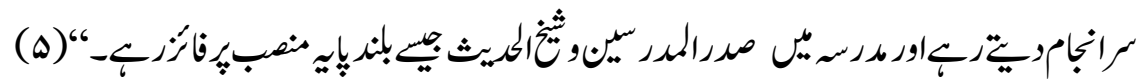




\section{ماروكميل خد مت ويّن}

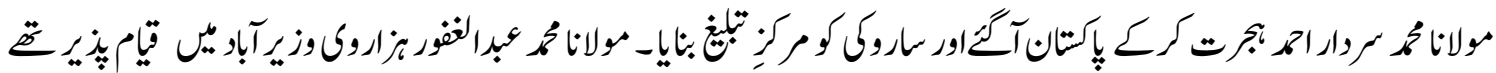

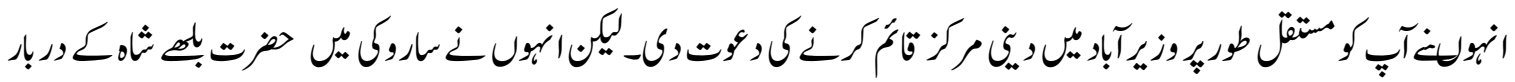

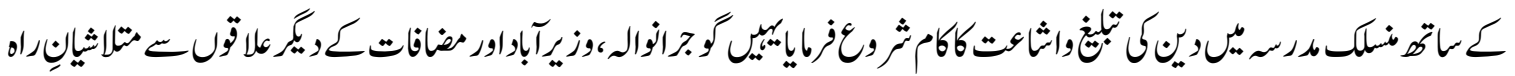

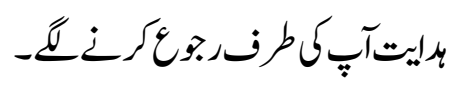

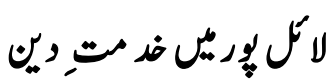

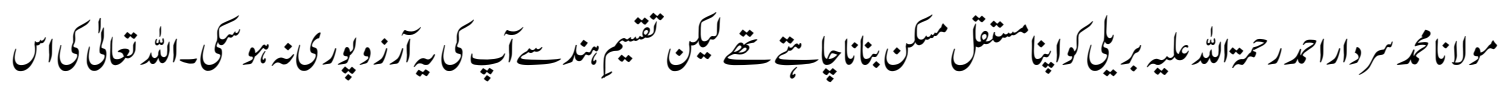

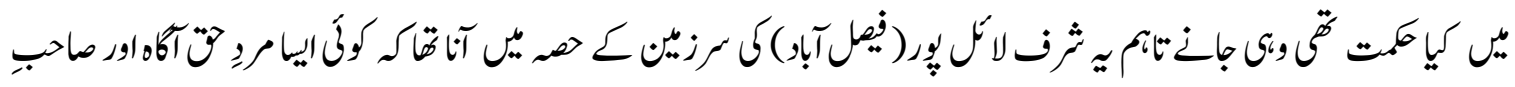

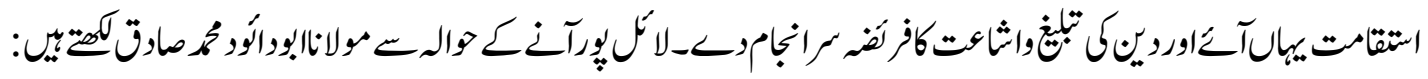

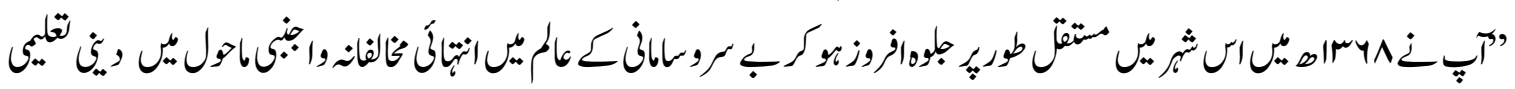

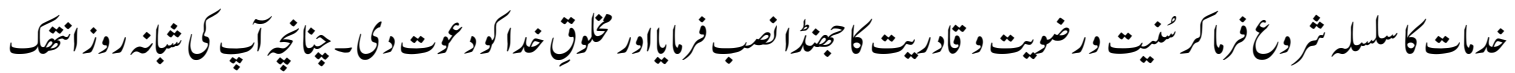

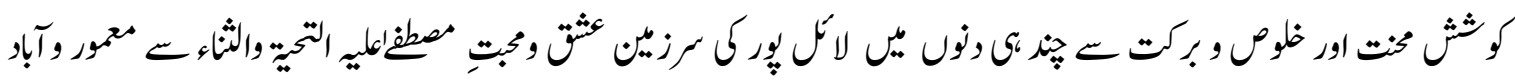

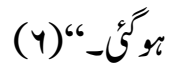

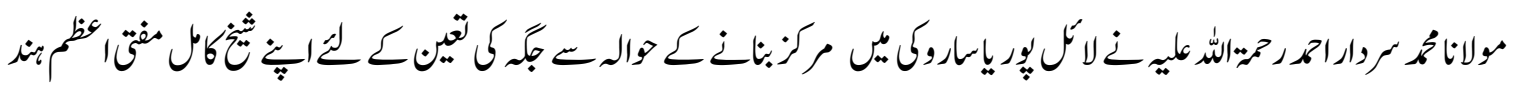

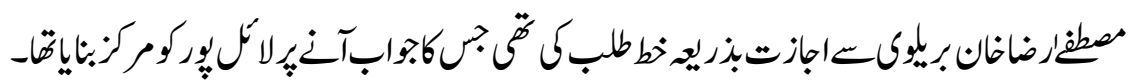

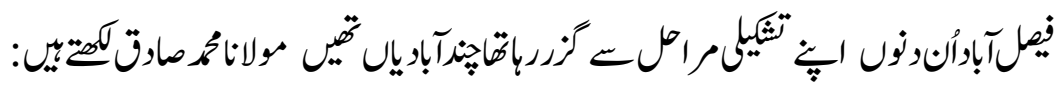

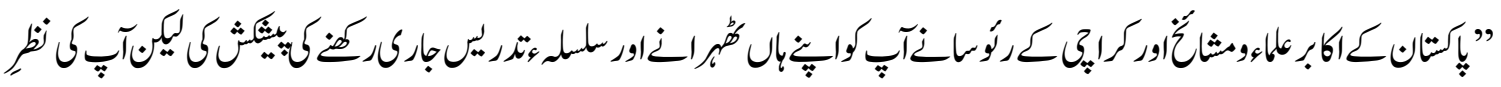

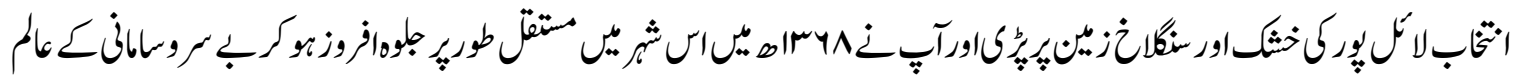

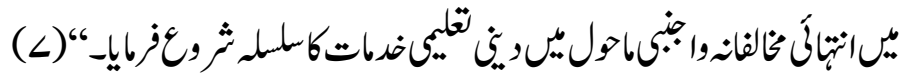

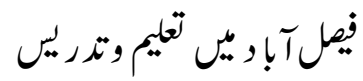

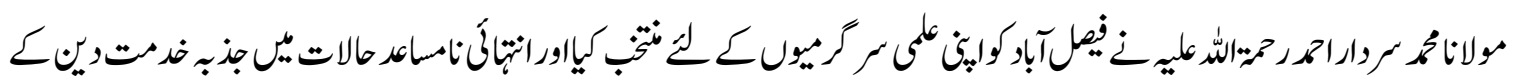

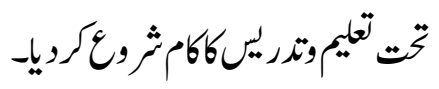

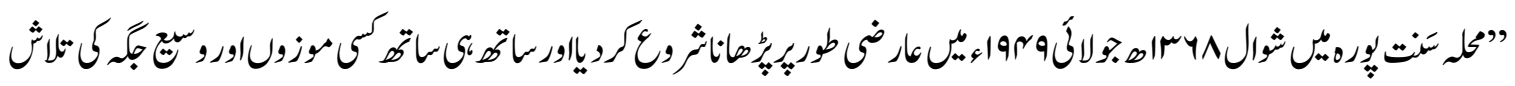

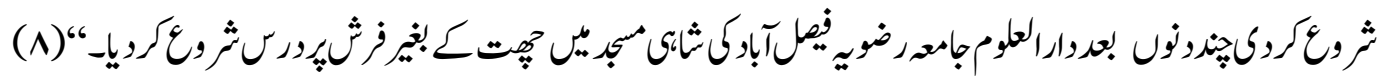




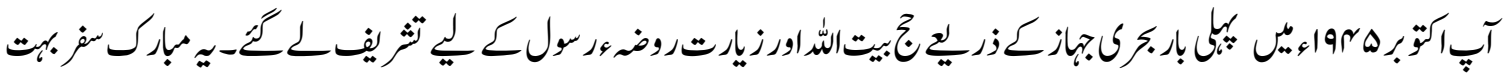

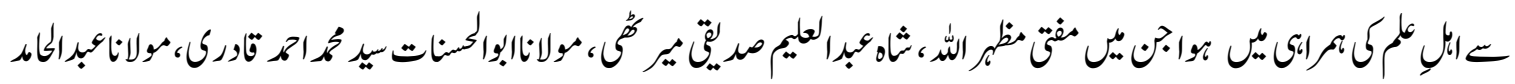

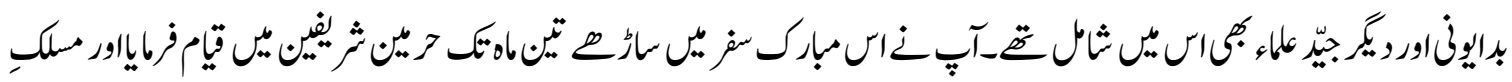

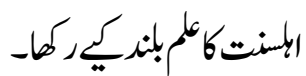

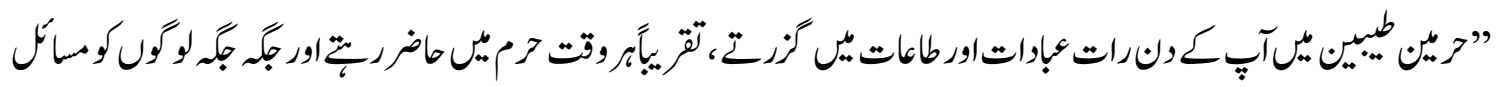

(9)_تمجمات

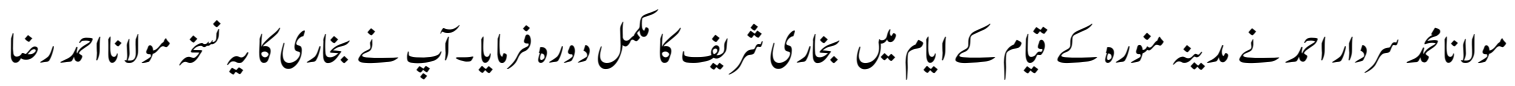

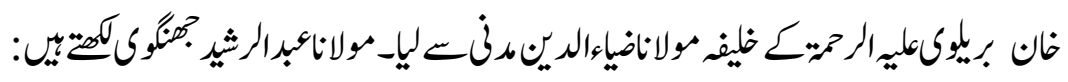

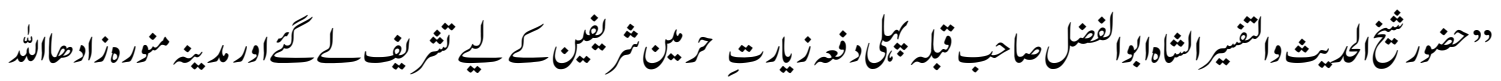

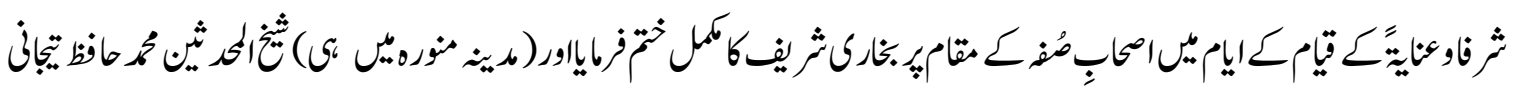

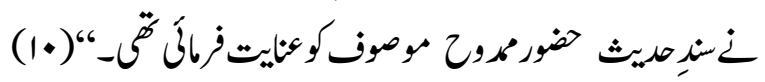
ورومراسزجُوزيارت

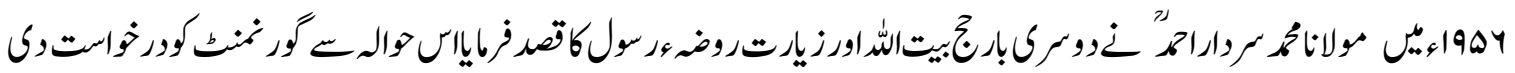

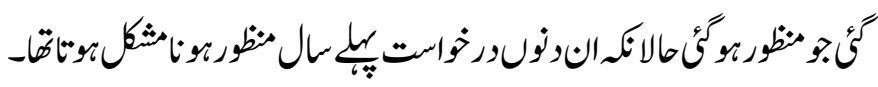

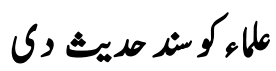

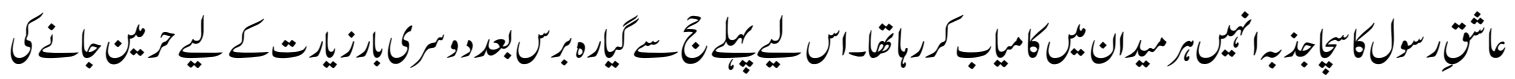

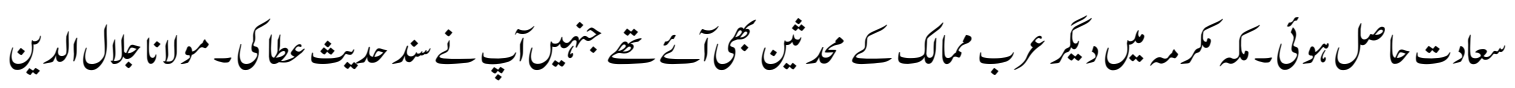

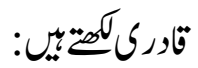

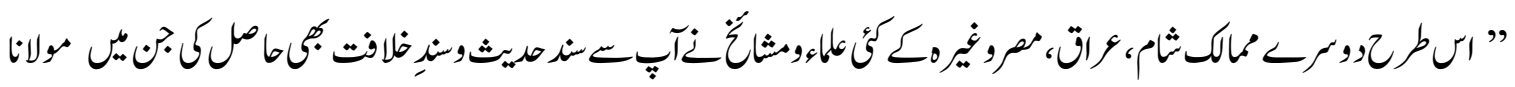

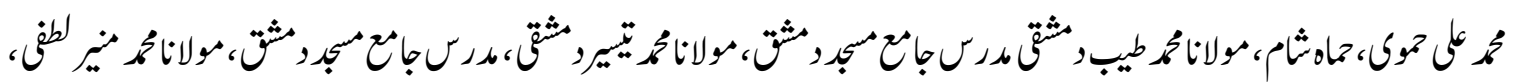

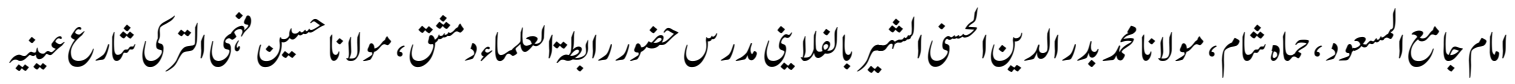

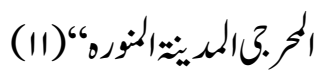




\section{بيت و ملا فت}

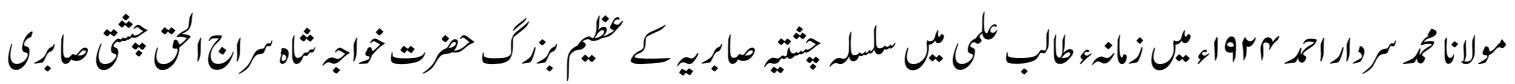

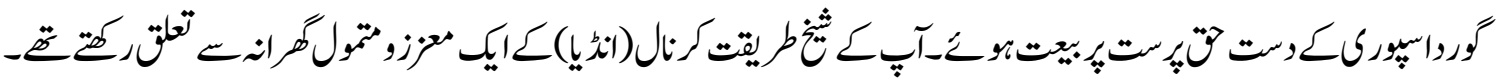

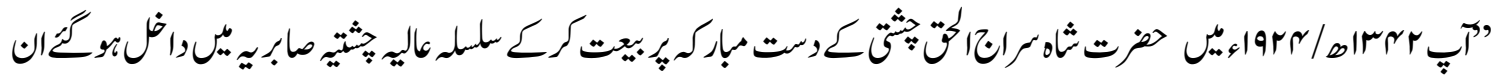

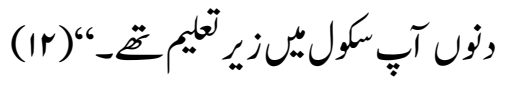

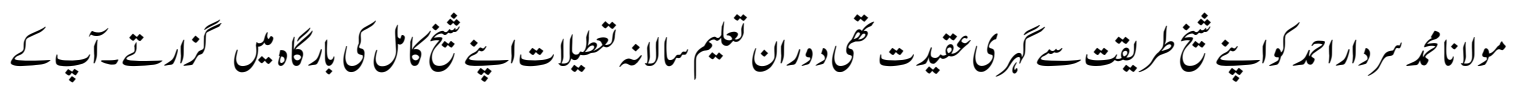

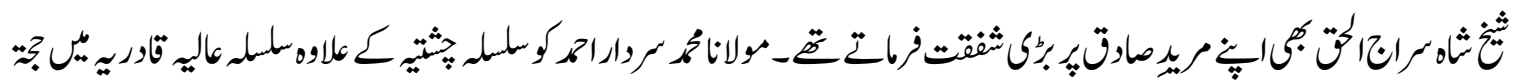

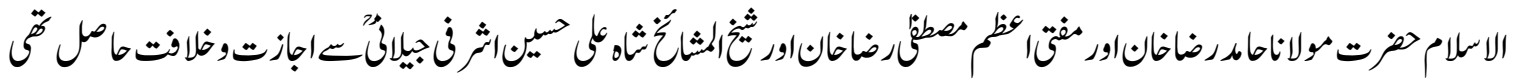

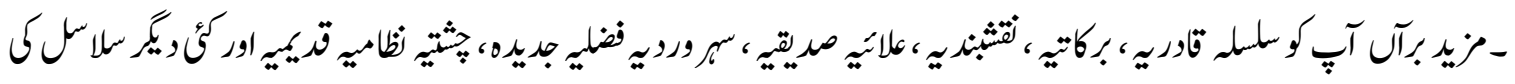

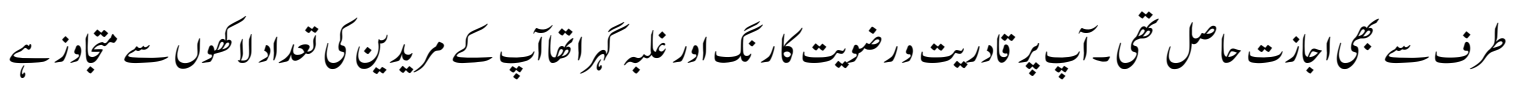

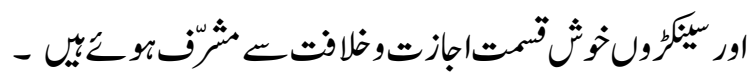

آب ك خلفاء

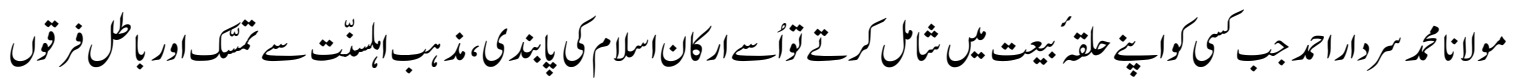

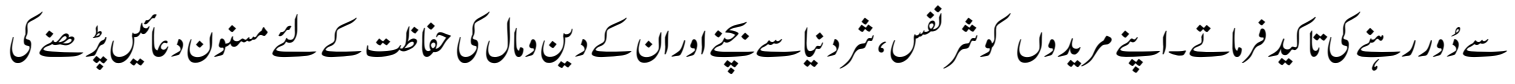

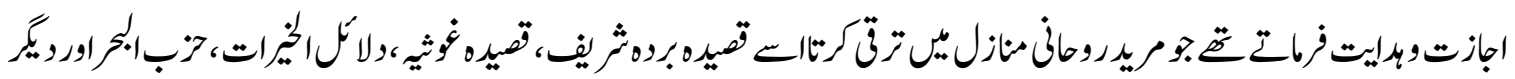

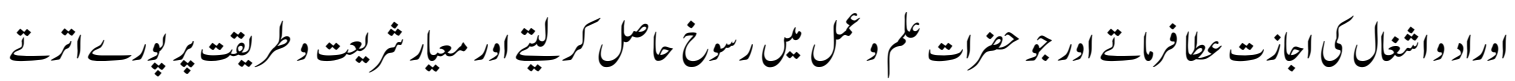

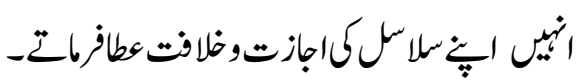

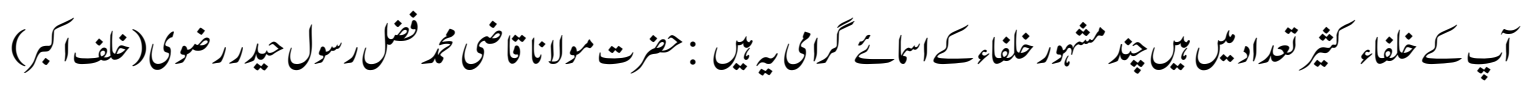

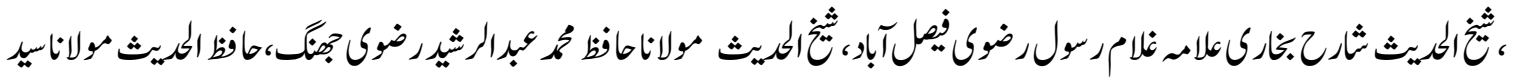

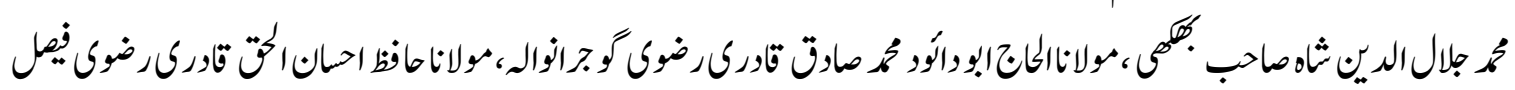

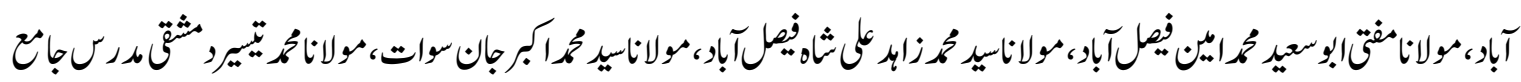

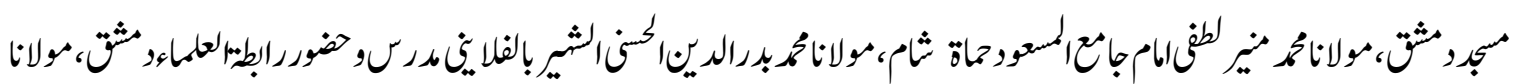

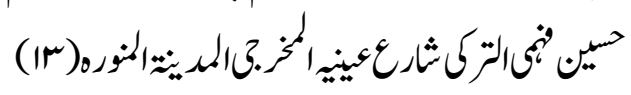




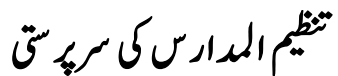

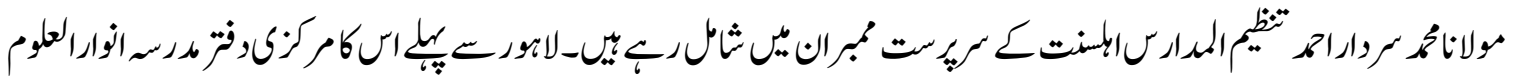

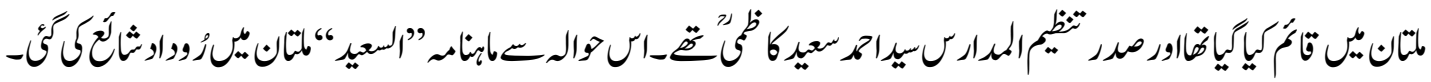

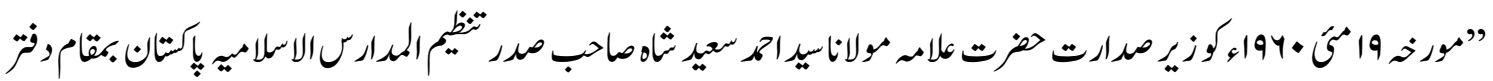

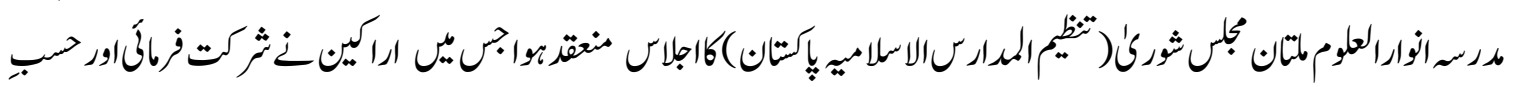

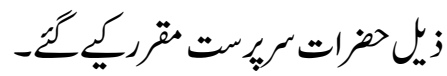

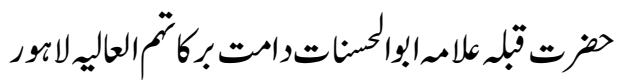

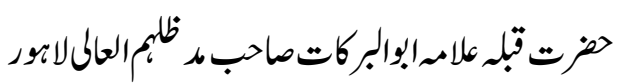

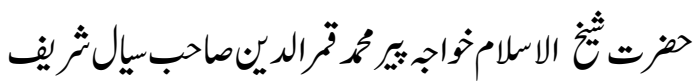

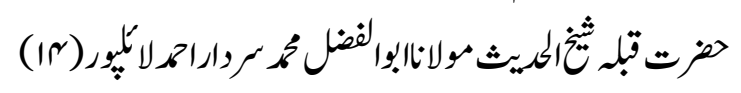

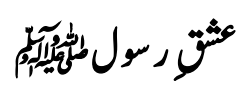

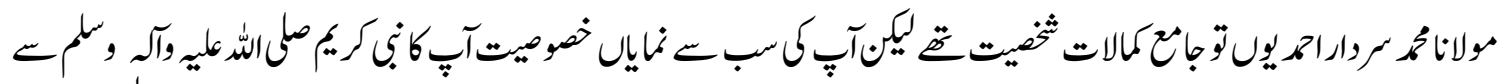

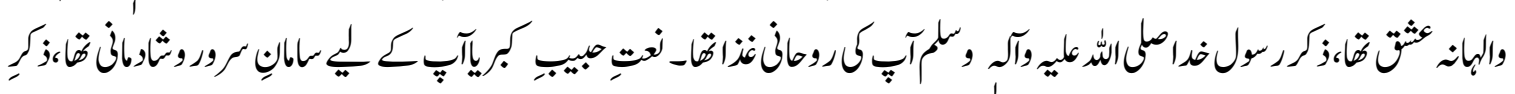

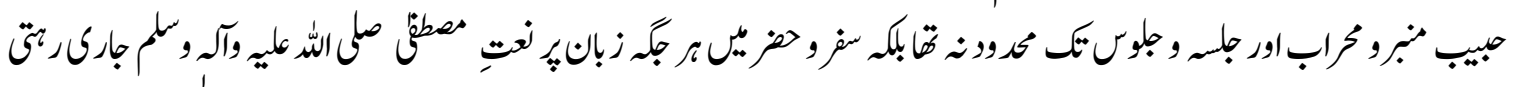

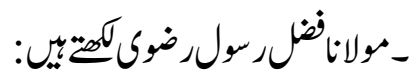

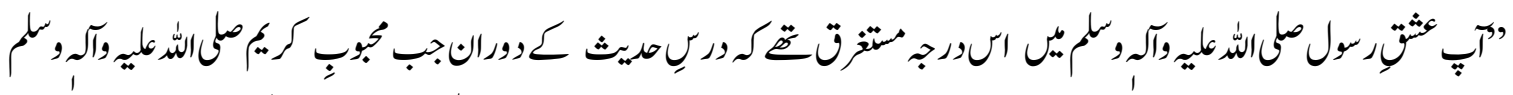

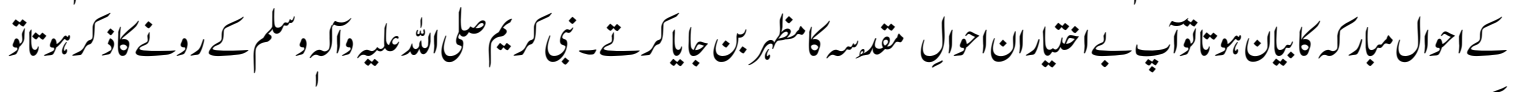

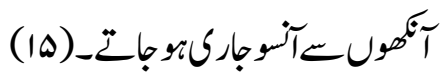

$$
\text { اتبإع سُنّْت }
$$

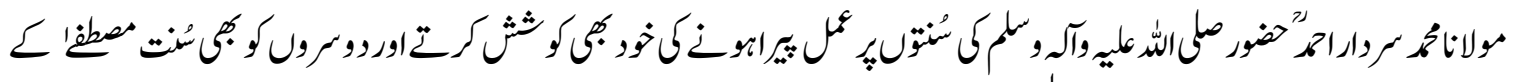

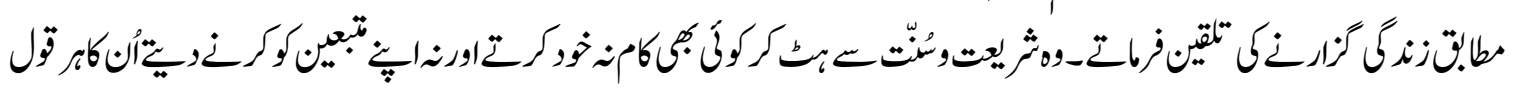

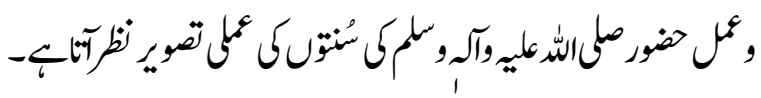
اح"ازم لارات

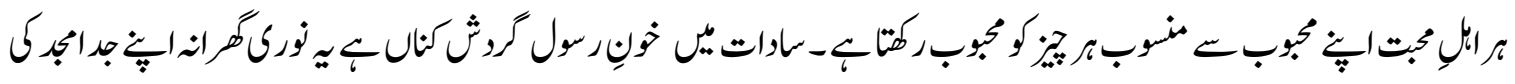




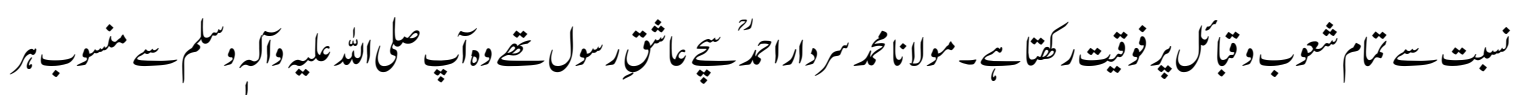

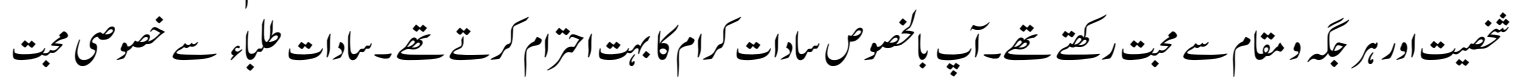

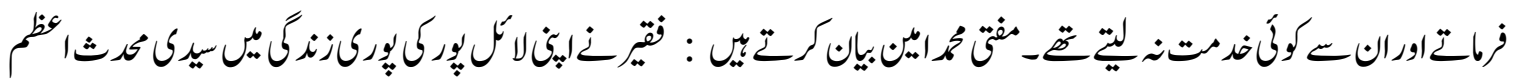

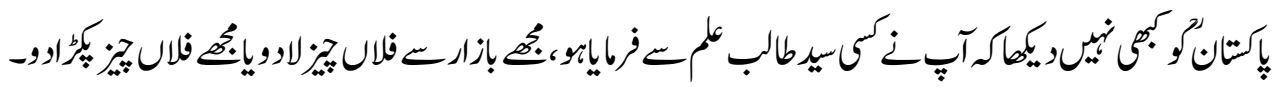

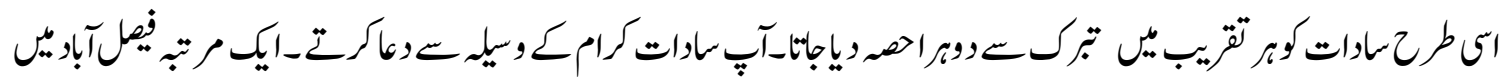

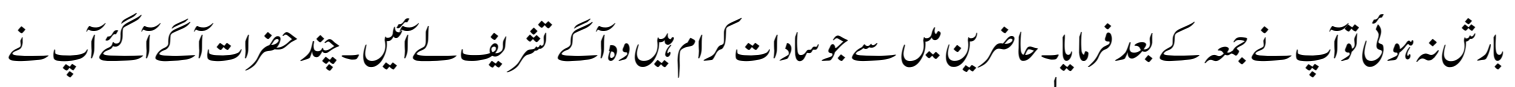

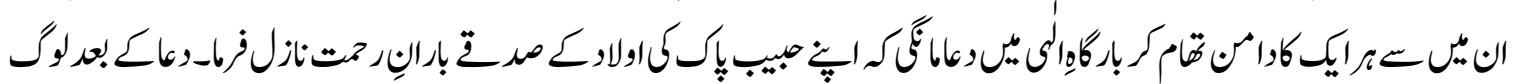

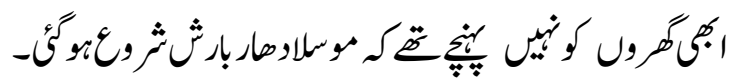

$$
\text { اولياءكرام مجبت }
$$

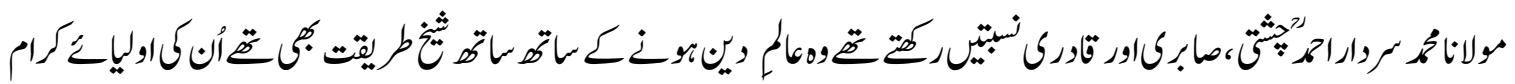

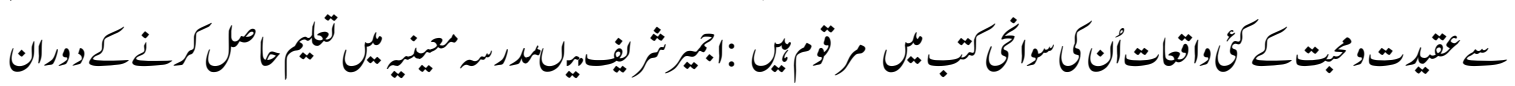

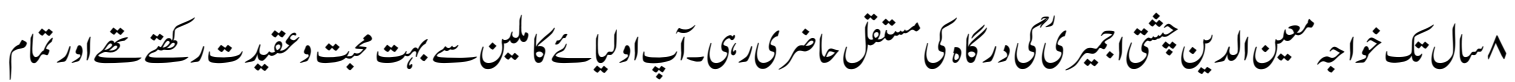

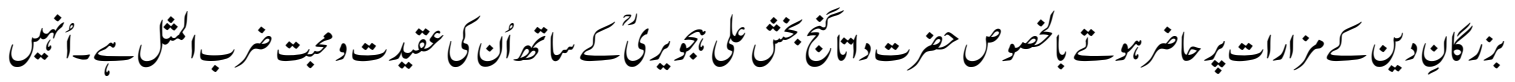

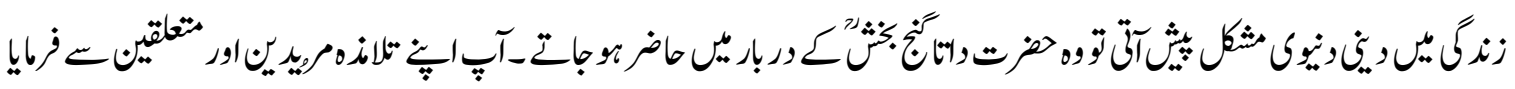

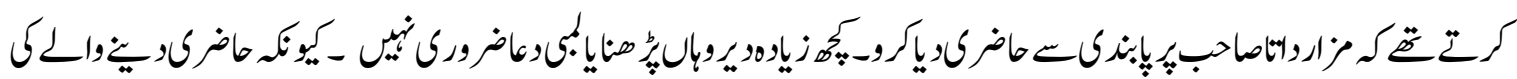

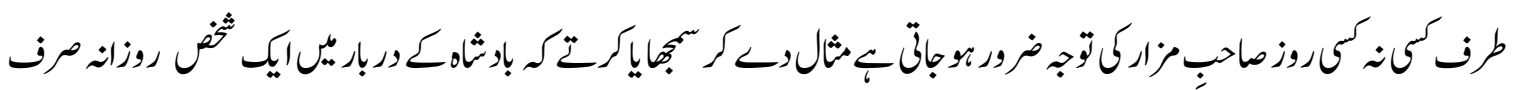

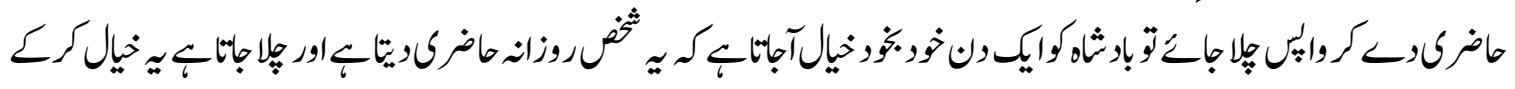

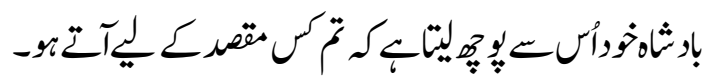

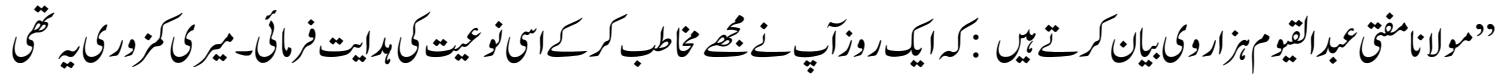

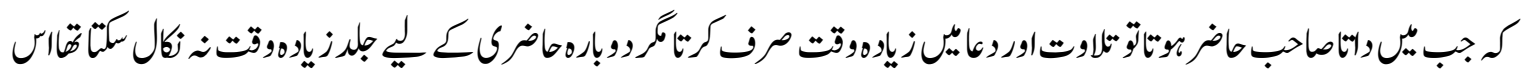

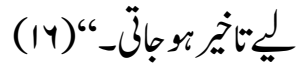

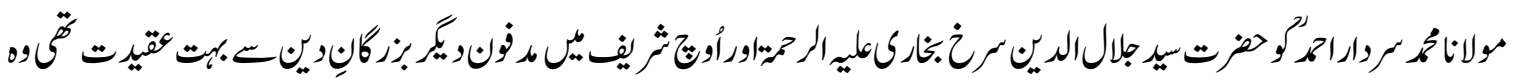

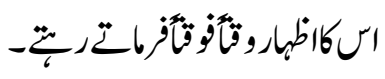




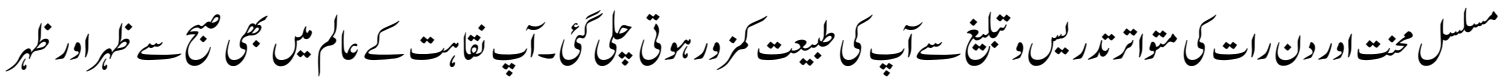

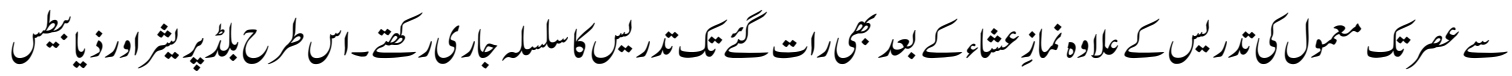

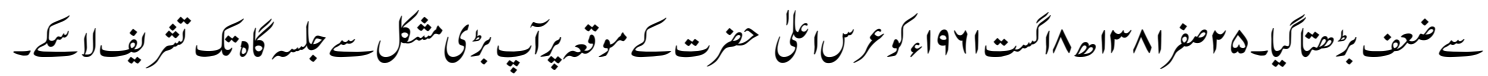

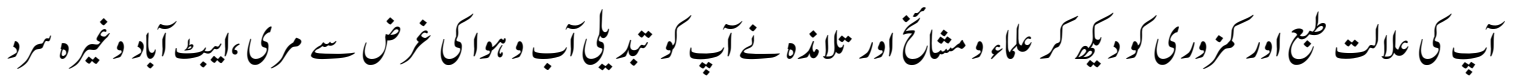

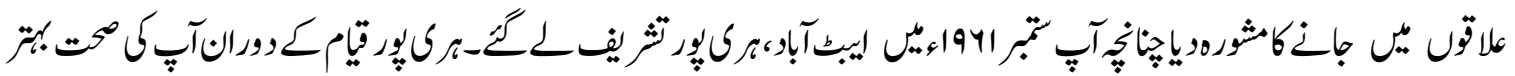

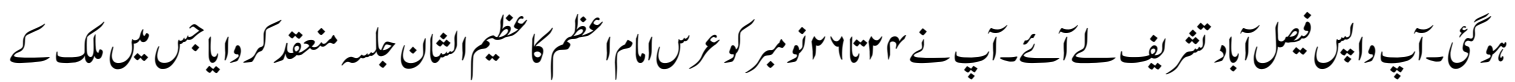

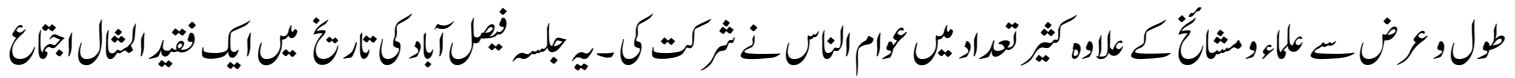

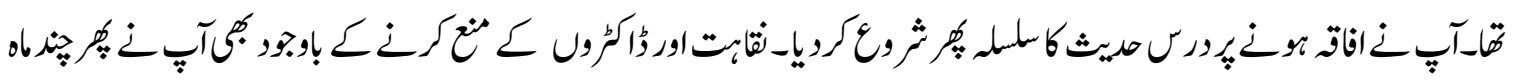

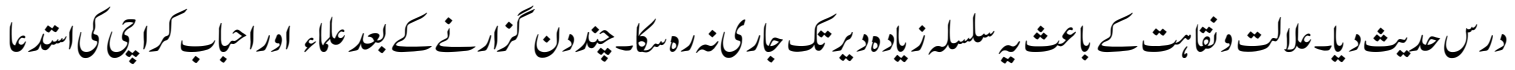

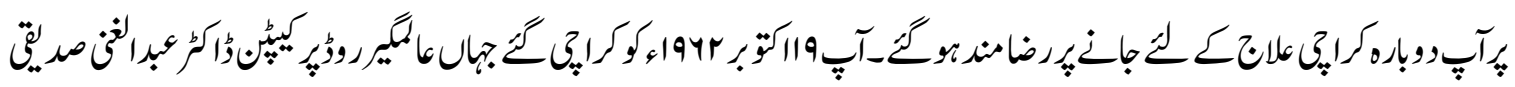

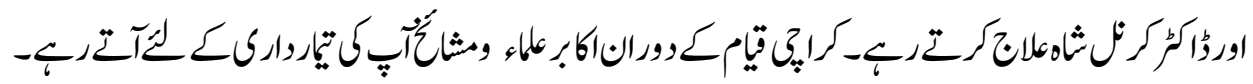

وصال

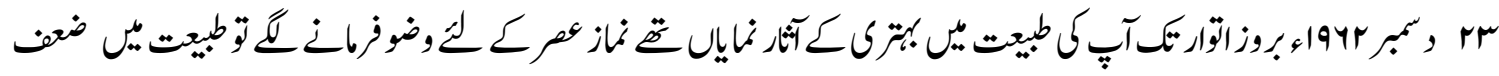

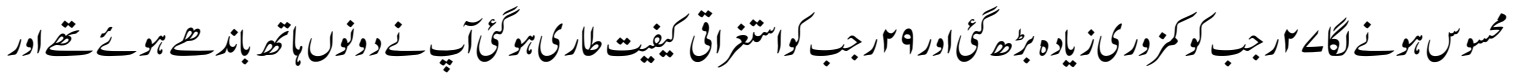

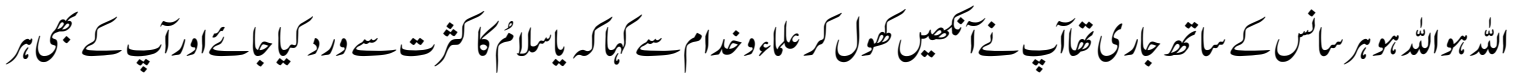

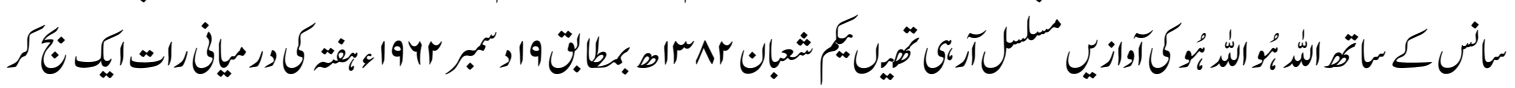

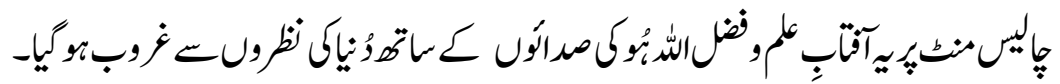

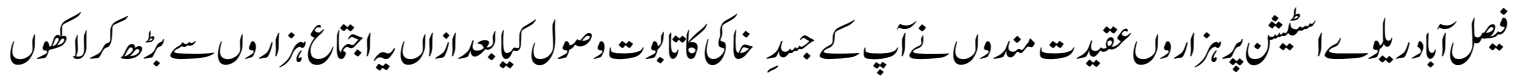

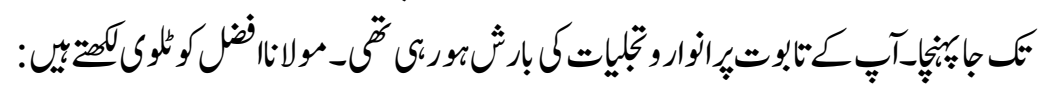

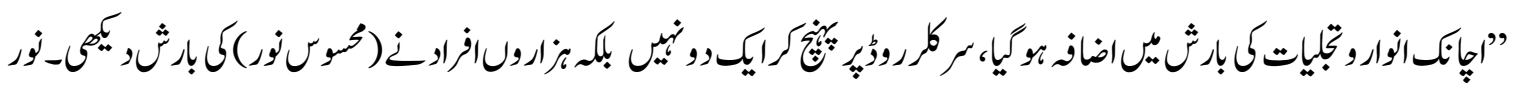

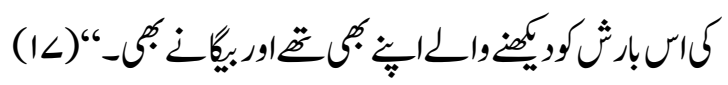

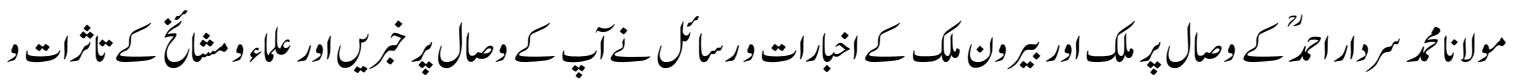

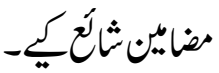




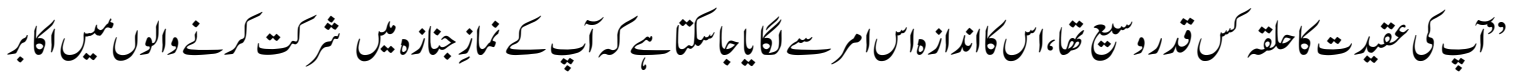

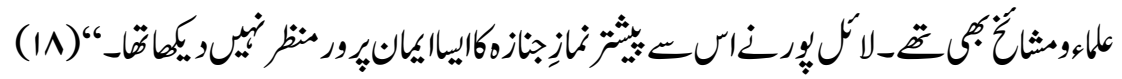
اولاواجار

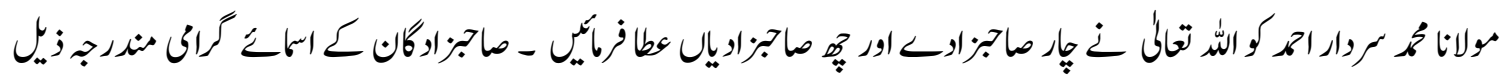

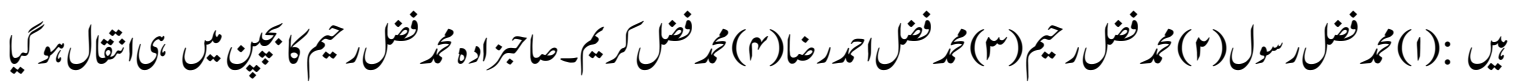

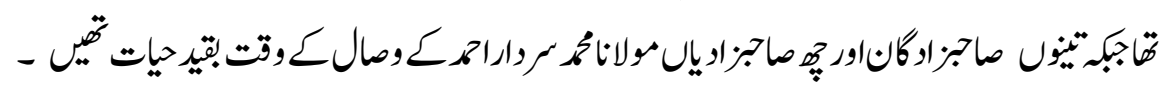

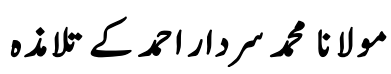

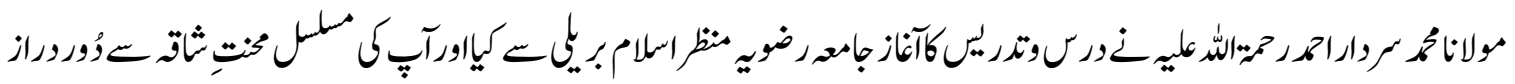

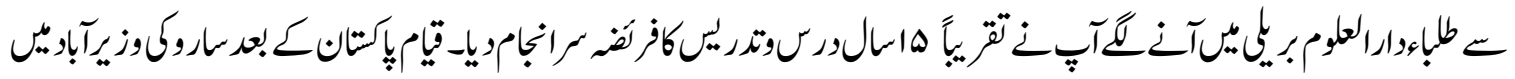

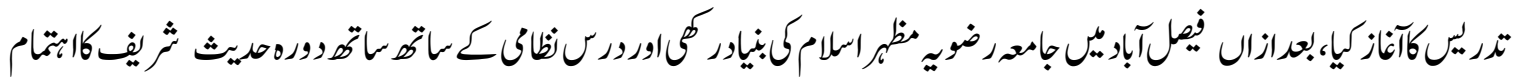

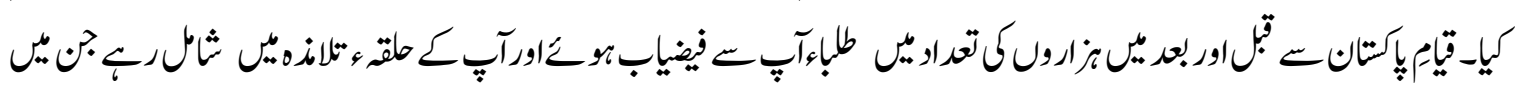

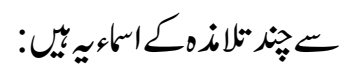

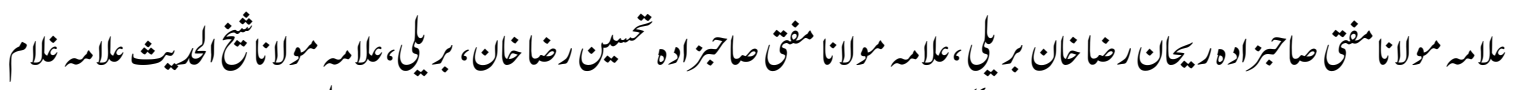

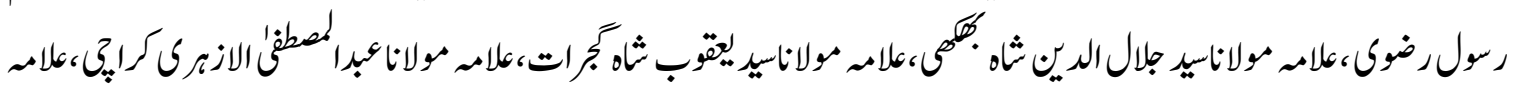

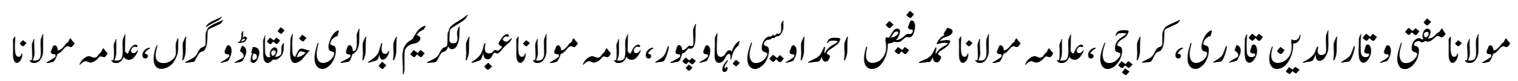

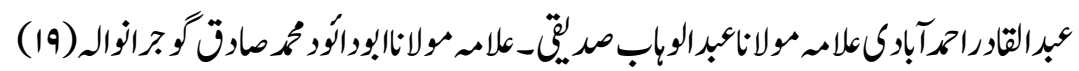

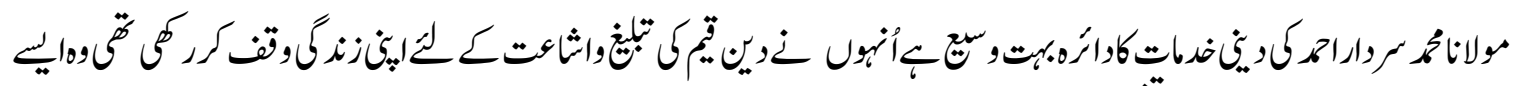

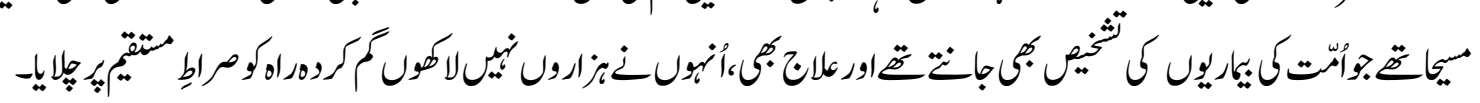

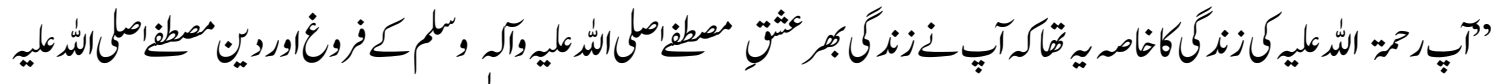

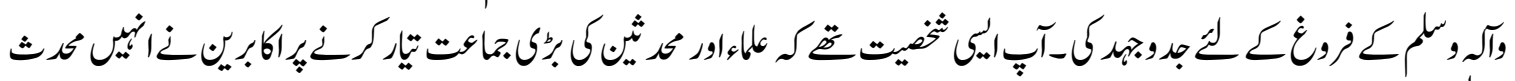

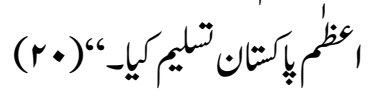

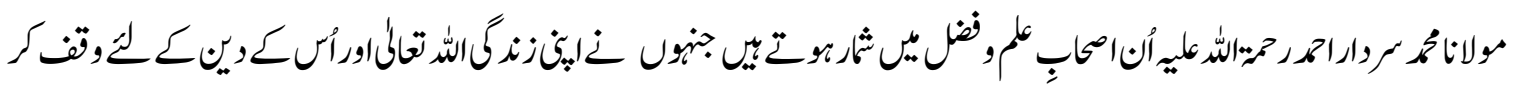

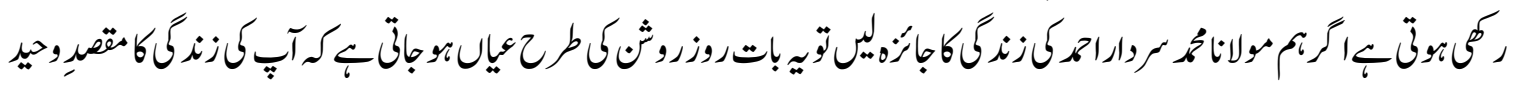
خدمتِّيناورلميت تقا 


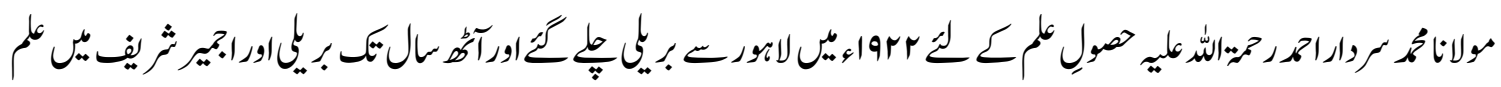

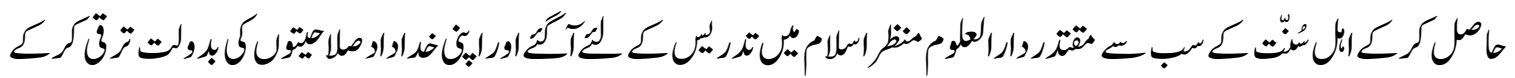

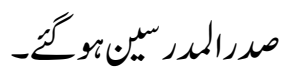

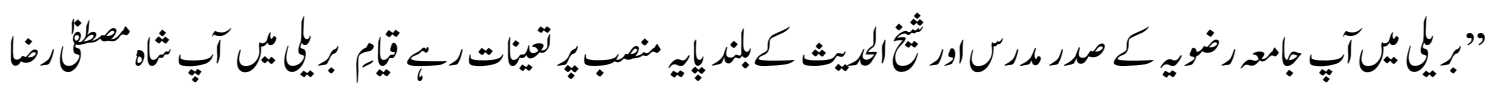

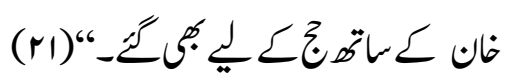

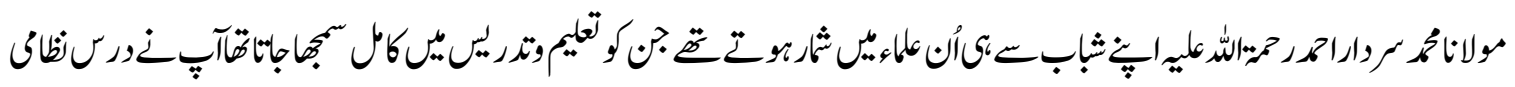

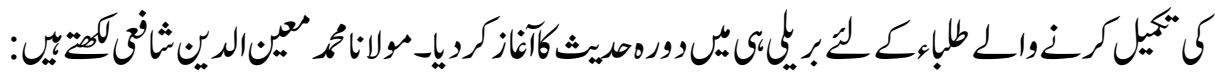

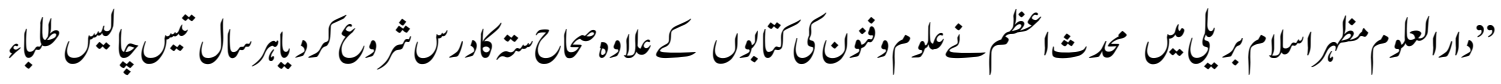

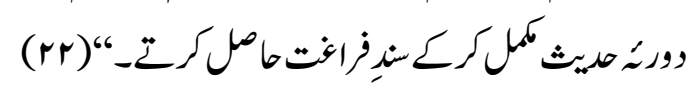

اندازِترديل

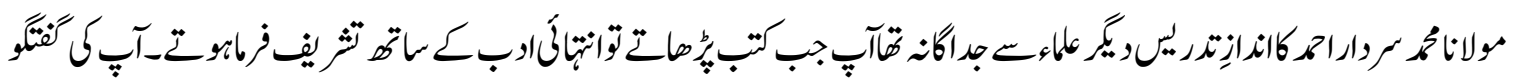

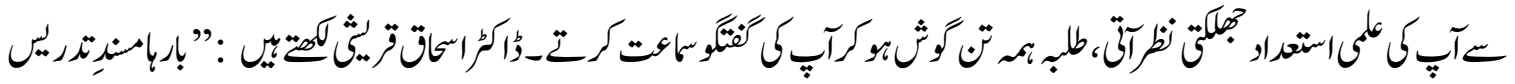

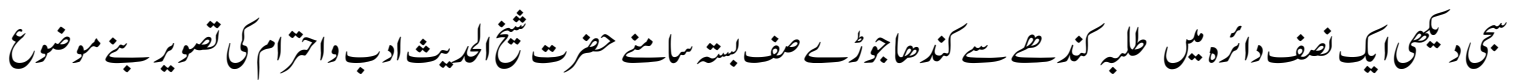

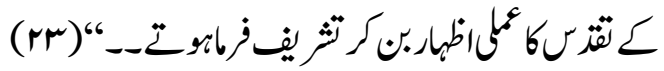

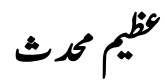

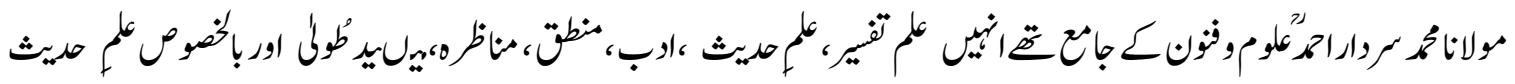

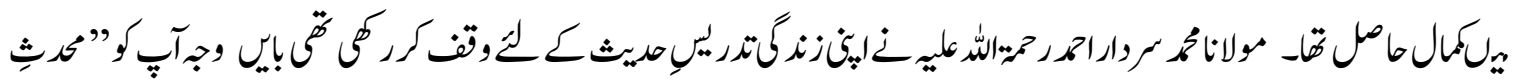

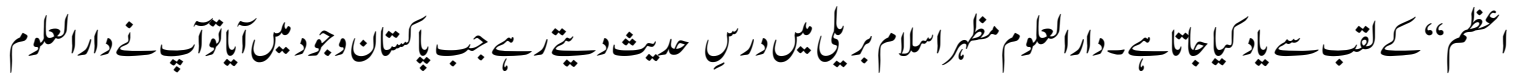

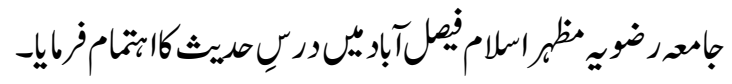

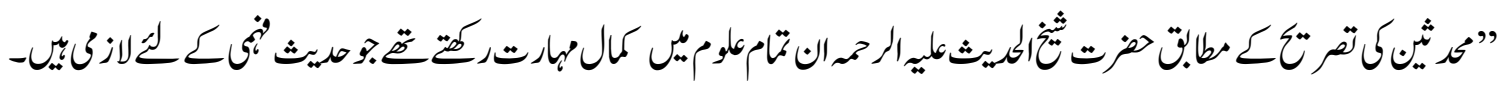

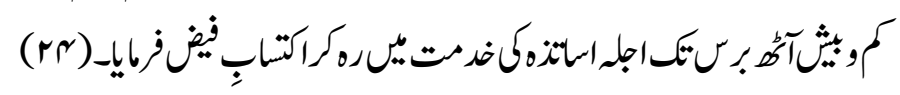

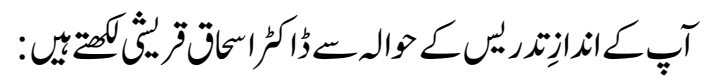

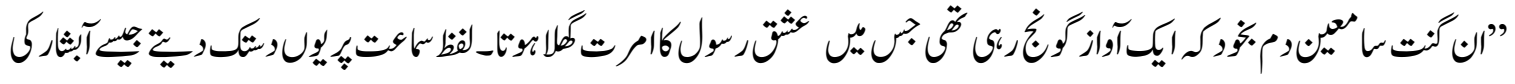




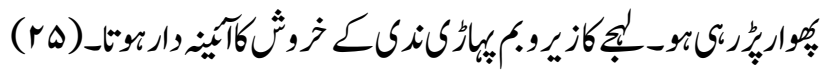

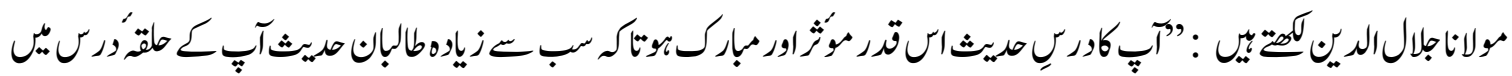

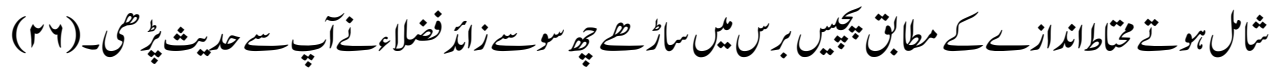

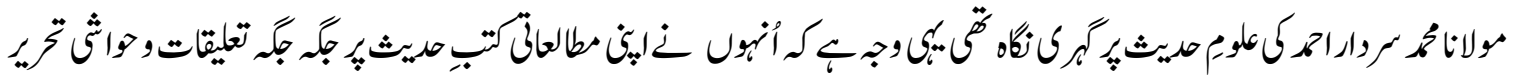

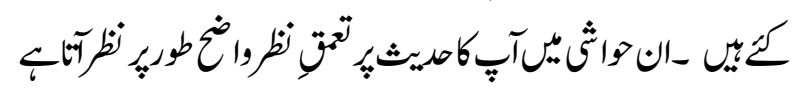

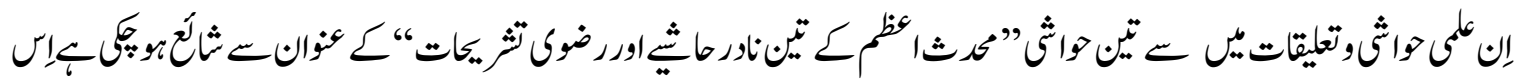

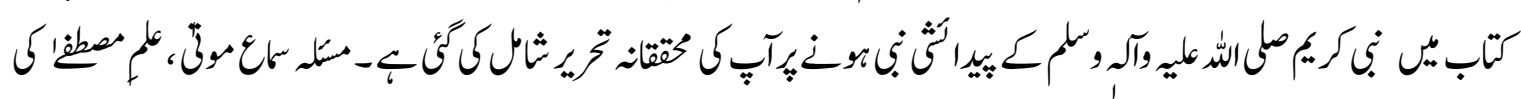

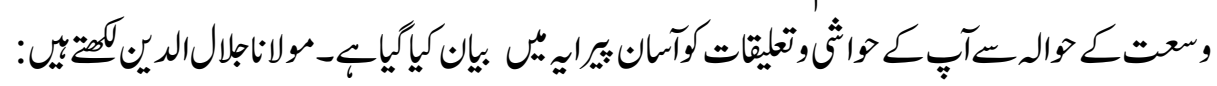

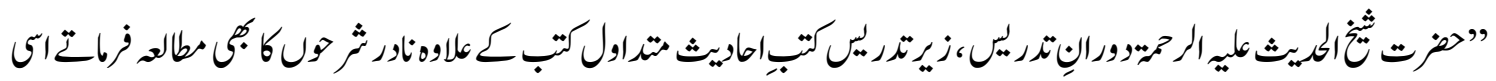

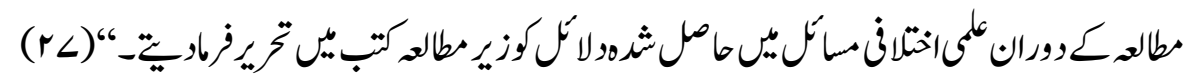

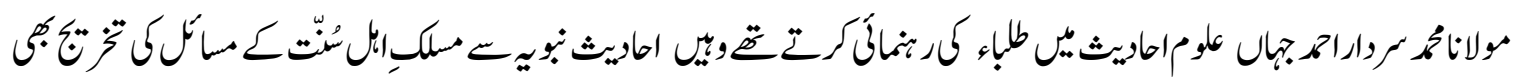

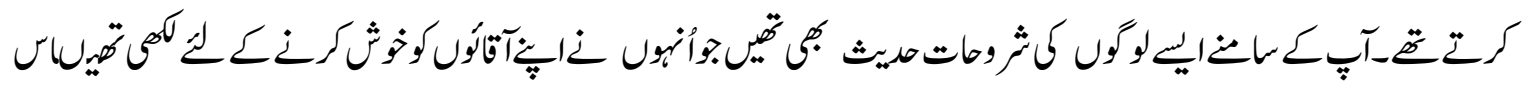

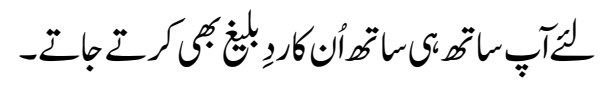

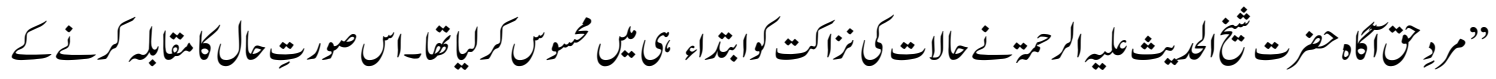

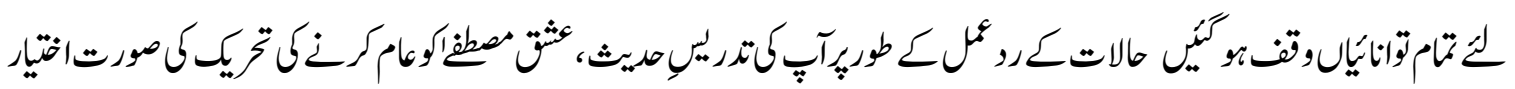

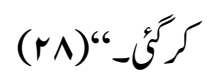

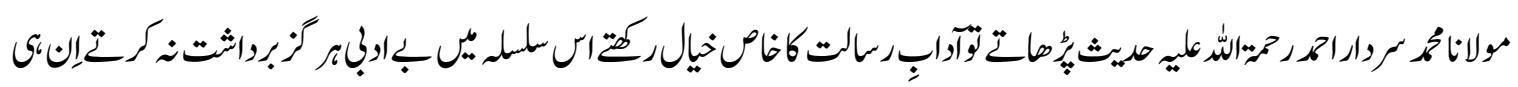

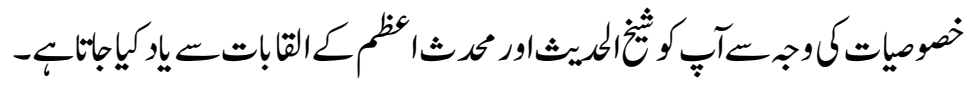

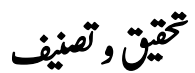

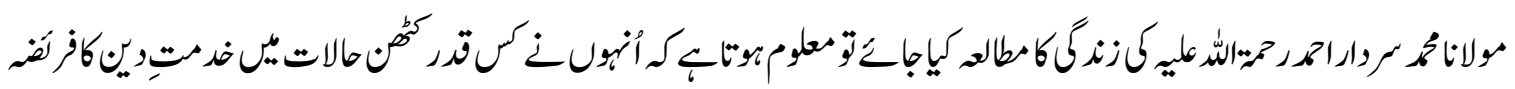

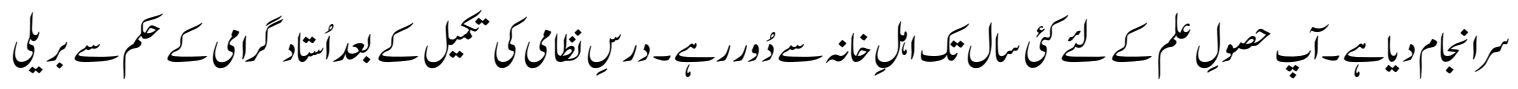

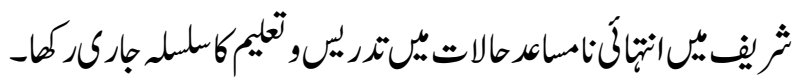

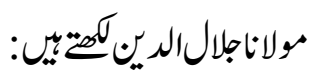

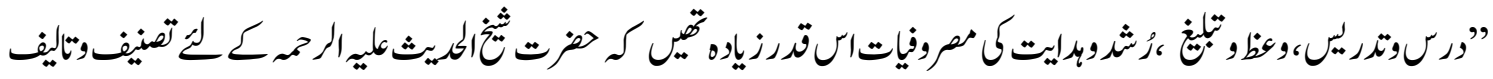




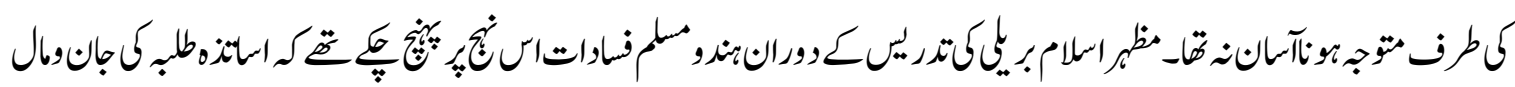

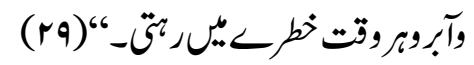

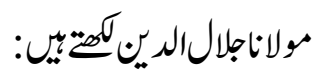

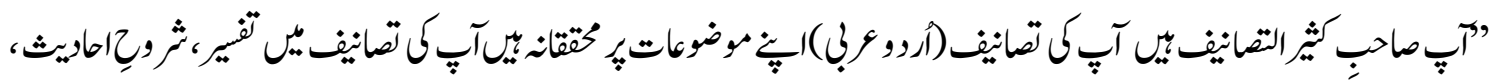

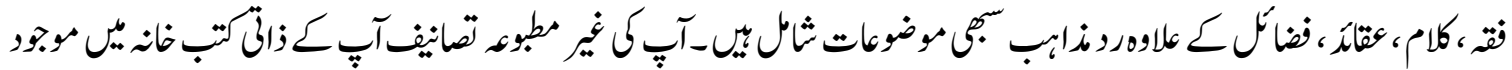
$(\mu \cdot)^{\prime \prime}-\omega^{\prime \prime}$

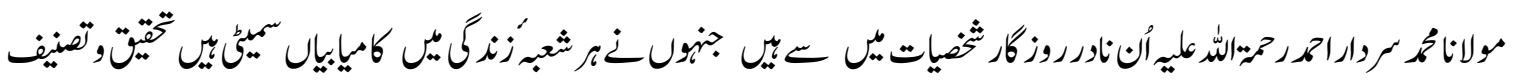

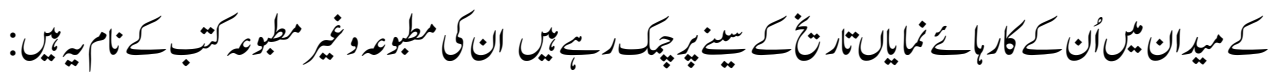
اـاسلاق قانولِِِوراثت r مبتوتكيغام

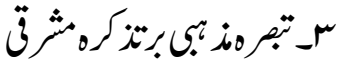

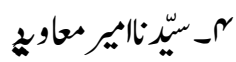

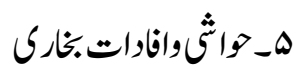

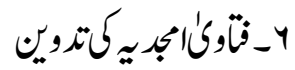

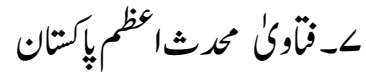

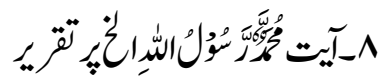

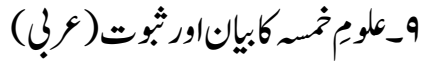

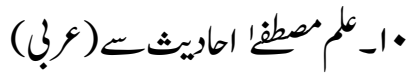

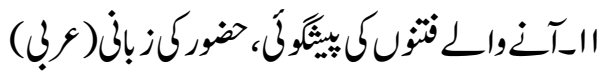

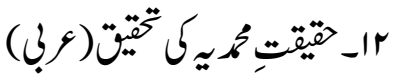

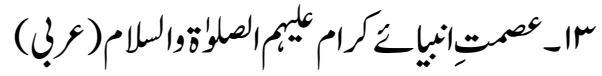

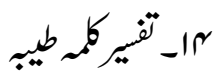
ها-مبيت حديث

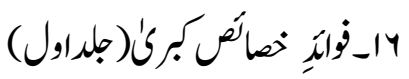




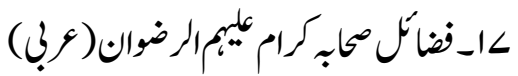

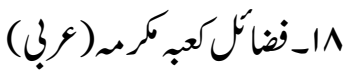

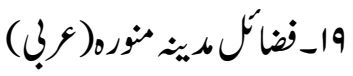

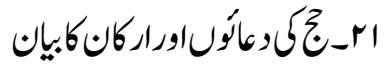

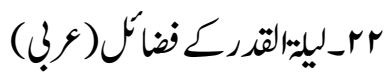
rr

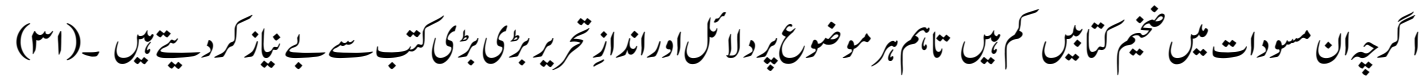

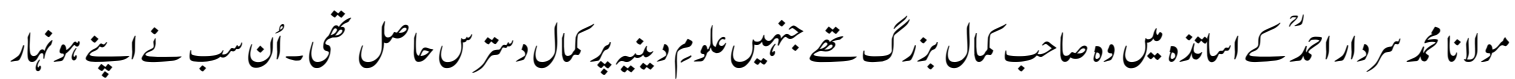

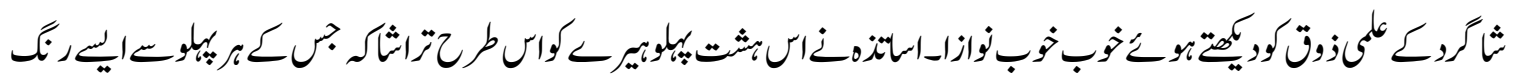

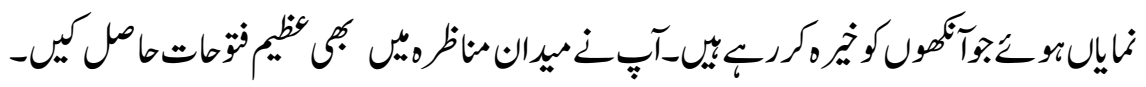

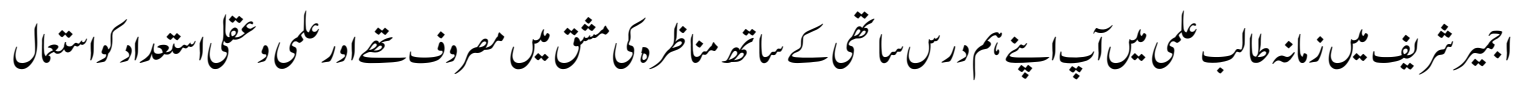

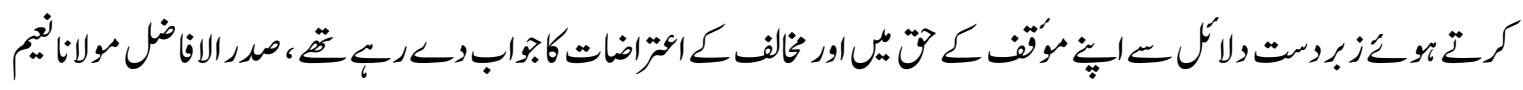

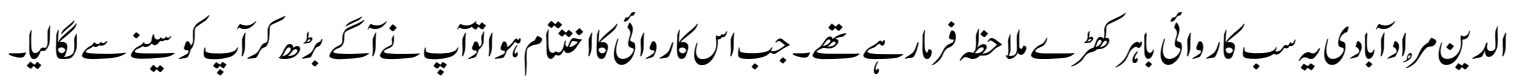

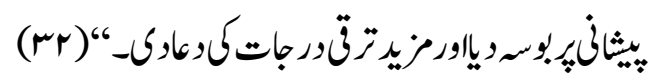

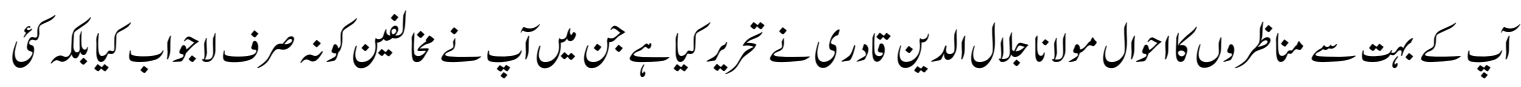

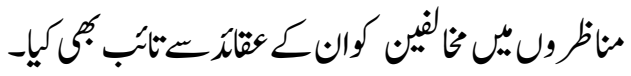

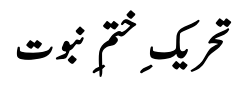

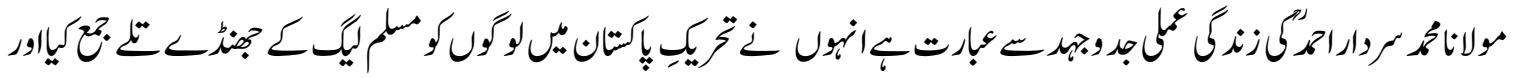

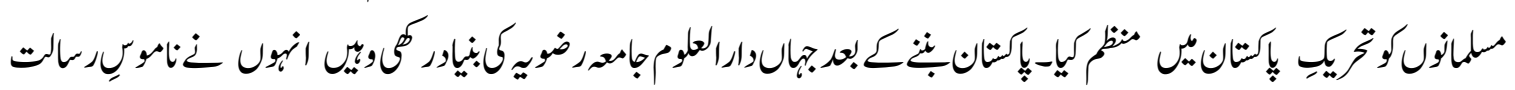

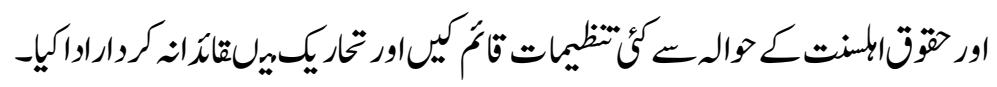

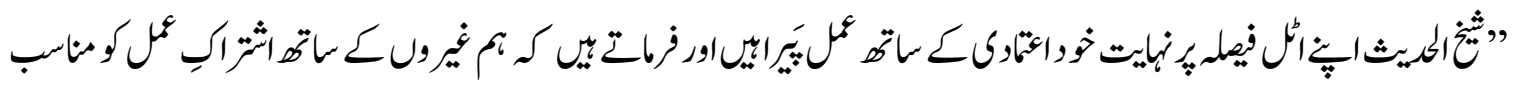

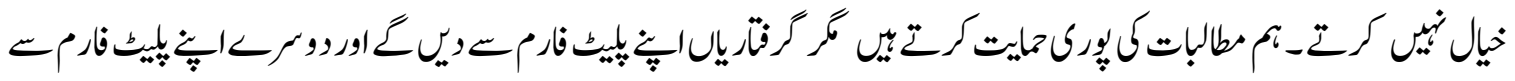




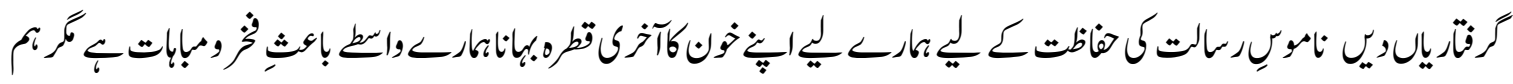

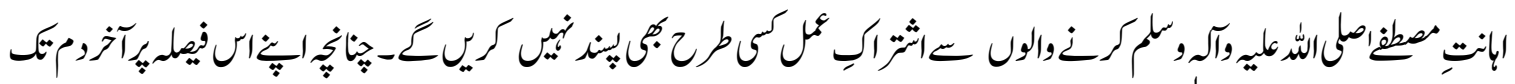

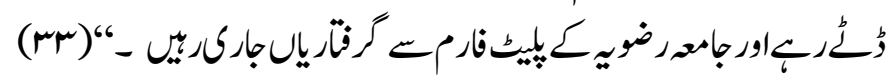

تخ كبـ نظام مصطو

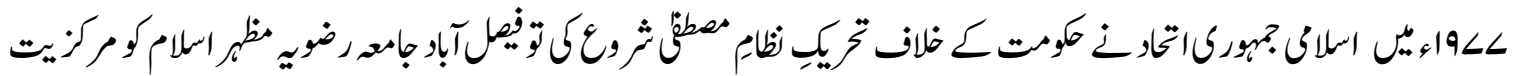

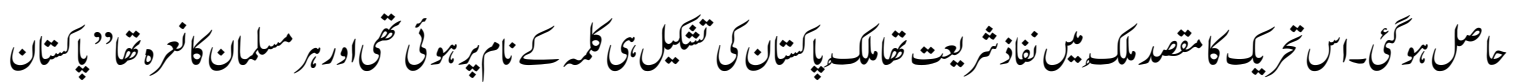

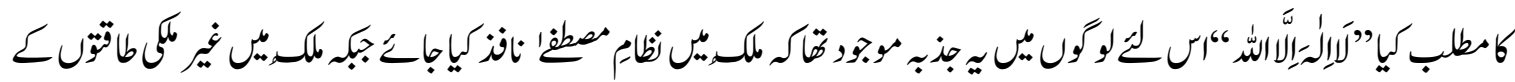

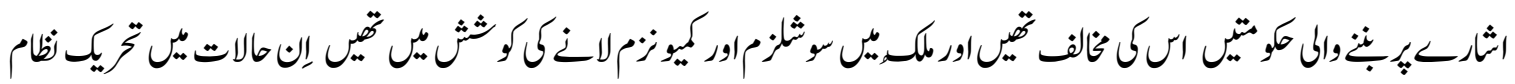

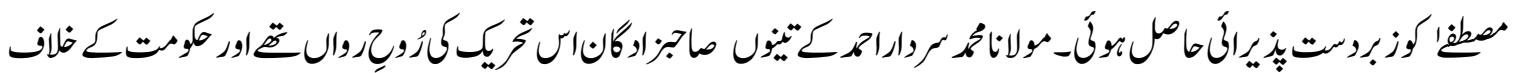

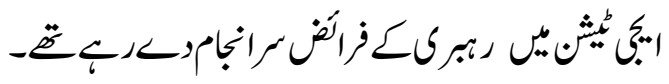

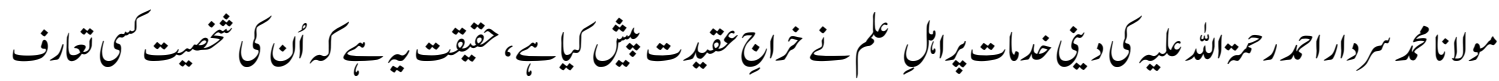

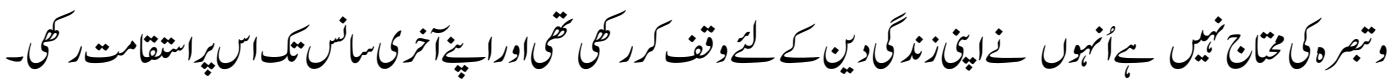
واله جات

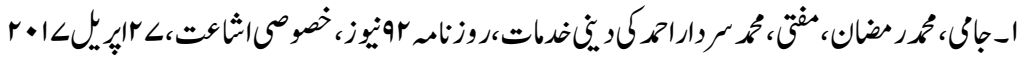

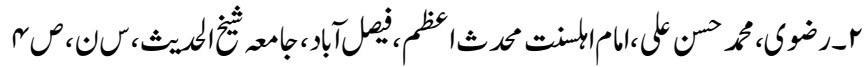

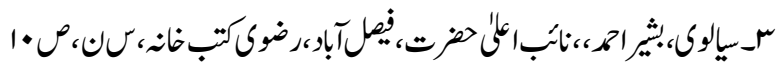

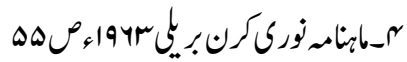

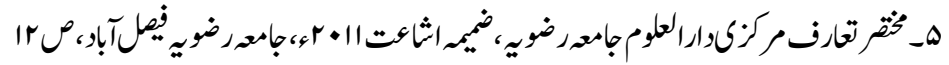

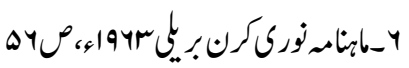

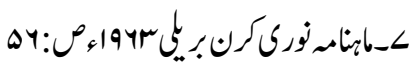

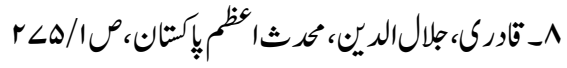

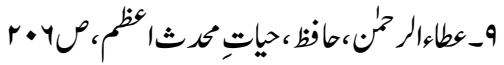

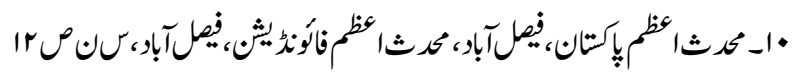

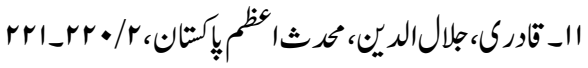

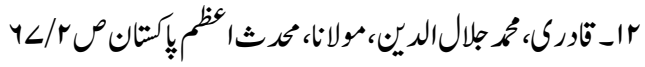

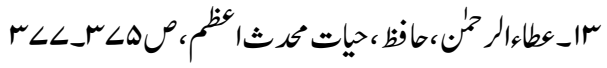




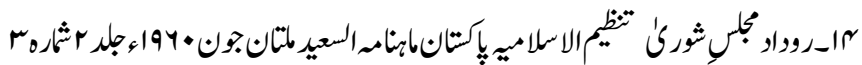

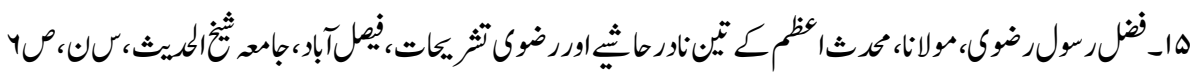

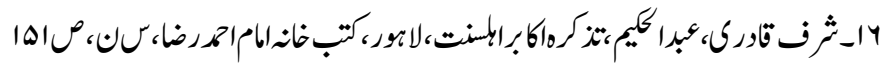

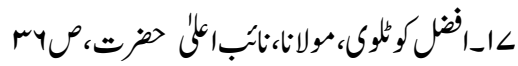

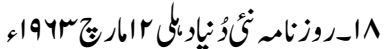

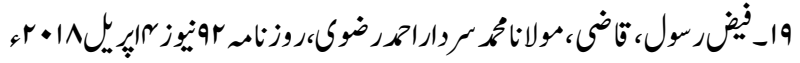

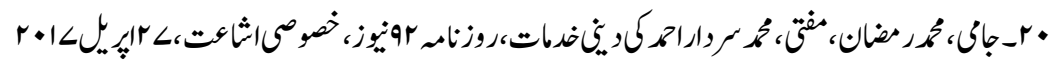

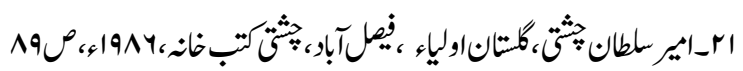

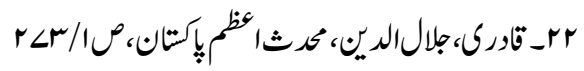

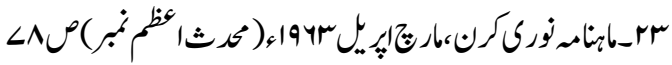

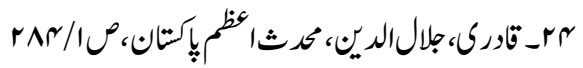

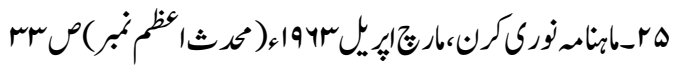

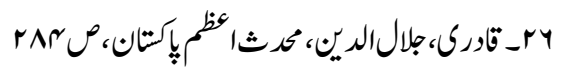

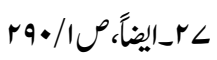

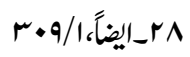

a

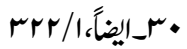

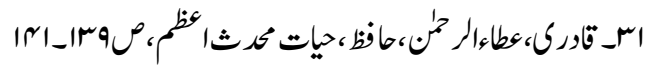

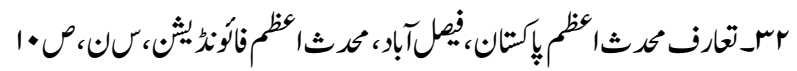

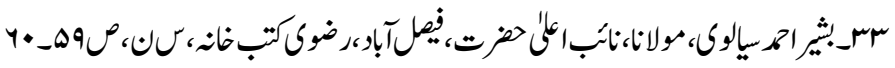

\section{References}

1. Jami,Muhammad Ramzan, mufti, Muhammad, Sardar Ahmad ki dini khidmat, Roznama92 nioz, khasosi ishat 27 April2017

2. Rizvi,Muhammad Hasan Ali Imam Ahl-i-sunat Mohaddis-i-Azam, Faisalabad, Jamia Shaikh-ulhadis, seen non, Safha 4

3. Sayyalvi,Bashir Ahmad, Naib Ala Hazrat,Faisalabad, Rizvi kutab khana, Seen non, Safha 10

4. Mahnama Nori kiran Barili1963 Safha 55

5. Mukhtasar taruf Markzi dar-ul-uloom Jamia Rizvia, Zamima Ishat 2011, Jamia Rizvia Faisalabad, Safha 12

6. Mahnama nori kiran Barili 1963, Safha 56

7. Mahnama nori kiran Barili 1963, Safha 56

8. Qadri, Jalal-al din ,Mohadis-i-Azam Pakistan, Safha 1/275

9. Ata-ul-rahman, Hafiz, Hayyat-i-mohaddis-i-azam, Safha 206 
10. Mohaddis-i-Azam Pakistan Faisalabad, Mohaddis-i-Azam Foundation, Faisalabad, seen non Safha 12

11. Qadri, Jalal-al-din,Mohaddis-i-Azam Pakistan,2/220-221

12. Qadri, Jalal-al-din,Mohaddis-i-Azam Pakistan, $2 / 27$

13. Ata-ul-rahman, Hafiz, Hayyat-i-mohaddis-i-azam, Safha $375-377$

14. Rodad Majlis-i-shora Tanzim-al-islamia Pakistan Mahnama-al-saeed Multan, june1960 jild 2 shamara3

15. Fazal-i-Rasool Rizvi, Molana, Mohddis-i-Azam ky teen Nadir Hashiay Aor Rizvi tashrihat, Faisalabad Jamia Shaikh-al-hadis, Seen non Safha 2

16. Sharf Qadri Abdul hakim, tazkia Akabar Ahl-i-Sunnat, Lahore, Kutab khana iamam Ahmad Raza, Seen non Safha 151

17. Afzal Cotalvi, Molana, Naib-i-Ala Hazrat Safha 36

18. Roznama nai dunya Dihli 12 march 1963

19. Faiz Rasool,Qadri,Molana,, Muhammad, Sardar Ahmad Rizvi Roznama92 nioz, 14April 2018

20. Jami,Muhammad Ramzan, mufti, Muhammad, Sardar Ahmad ki dini khidmat, Roznama92 nioz, Khasosi Ishat, 27 April 2017

21. Amir Sultan Chishti, Ghulstan Aoliya, Faisalabad Chishti kutab khana,1986,Safha 89

22. Qadri, Jalal-al din ,Mohadis-i-Azam Pakistan, Safha 1/273

23. Mahnama nori kiran Barili 1963,(Mohadis-i-Azam Number) Safha 78

24. Qadri,Jalal-al-din Mohaddis-i-azam Pakistan, Safha 1/284

25. Mahnama nori kiran Barili 1963,(Mohadis-i-Azam Number) Safha 33

26. Qadri,Jalal-al-dinMohaddis-i-azam Pakistan, Safha $1 / 284$

27. Aizan, Safha $1 / 290$

28. Aizan, $1 / 309$

29. Aizan, $1 / 321$

30. Aizan, $1 / 322$

31. Ata-ul-rahman, Hafiz, Hayyat-i-mohaddis-i-azam, Safha 139-141

32. Mohaddis-i-Azam Pakistan Faisalabad, Mohaddis-i-Azam Foundation, Faisalabad, seen non Safha 10

33. Sayyalvi,Bashir Ahmad, Naib Ala Hazrat,Faisalabad, Rizvi kutab khana, Seen non, Safha 59-60. 